\title{
Body composition: the precision and accuracy of new methods and their suitability for longitudinal studies
}

\author{
BY M. F. FULLER ${ }^{1}$, P. A. FOWLER ${ }^{2}$, G. MCNEILL1 \\ AND M. A. FOSTER ${ }^{2}$ \\ ${ }^{1}$ Rowett Research Institute, Bucksburn, Aberdeen AB2 9SB \\ ${ }^{2}$ University of Aberdeen, Department of Biomedical Physics and Bioengineering, Foresterhill, \\ Aberdeen $A B 92 Z D$
}

The ability to estimate body composition is of central importance in studies of growth and nutrition, in both animals and man. However, what we mean by body composition and what we wish to estimate differ according to how we view the body. Anatomists may think in terms of the sizes of organs and tissues, physiologists in terms of cellular and extracellular components, nutritionists in terms of nitrogen, lipid or energy contents, animal breeders or butchers in terms of meat, fat and bone. The methods we choose to estimate body composition reflect these different viewpoints. Our aims also dictate the precision we require of our techniques and, since it is generally true that precision is expensive (Kempster, 1984), we need at the outset to define our aims rather carefully, in the form of two questions:

what information is needed?

how accurate and how precise must it be?

\section{APPROACHES TO DESCRIBING BODY COMPOSITION}

Methods of estimating body composition, whether in living subjects or destructively, have been of two kinds, those which describe the chemical composition of the body and those which describe the anatomical distribution of tissues. In the first, the body is treated as if it contained a homogeneous mixture of substances, and, for the purposes of estimation, it would be far better if it did, for inhomogeneity is a major source of difficulty in many of these methods. Destructive techniques of this kind are exemplified by homogenizing the whole carcass and determining the water, $\mathrm{N}$ and lipid contents. In the second category, interest centres on determining the sizes and weights of individual bones, muscles and so on, classically by dissection. For much nutritional work methods in the first category have been of most interest, but with greater understanding of the factors controlling tissue growth it becomes increasingly important to have information of both kinds. Recent findings on the effects of adipose tissue distribution on the metabolic complications of obesity (Kissebah et al. 1982; Krotkiewski et al. 1983) and on regional differences in lipid storage and mobilization (Rebuffe-Scrive et al. 1985) emphasize this need. For studies with small and even large animals the destructive technique of comparative slaughter with dissection or homogenization of the carcass is very widely used and is often the most cost-effective method. The need for nondestructive techniques arises:

(1) in human studies,

(2) with valuable animals,

(3) where the sequential study of individuals is necessary or desirable. 
Each of the destructive approaches has its non-destructive counterparts and the main aim of the present review is to discuss some of the more recent approaches to the estimation of body composition in vivo. However, since a rather similar subject was covered at a recent meeting of the Society by much the same authors (Foster et al. 1988) and the Society's Nutrition Research Reviews has recently published a review of body composition measurements (Coward et al. 1988), the present review will generally avoid covering the same ground.

\section{METHODS BASED ON CHEMICAL COMPOSITION}

A basic and generally useful concept in the estimation of body composition in vivo has been that the body can be considered as consisting of a fat-free (meaning lipid-free) empty-body mass which is of virtually constant composition with a highly variable superaddition of lipid (Fig. 1). (The word 'fat' is used sometimes to describe lipid, sometimes adipose tissue and these terms have been used to avoid ambiguity.) Many methods of estimating body composition in vivo depend on the ability to estimate one component of the lipid-free empty body (water or potassium, for example), from which the lipid-free mass as a whole can be estimated. The constancy of the composition of the lipid-free body mass is, however, relative. During growth from birth to maturity there are progressive and broadly predictable changes in the protein, water and electrolyte concentrations in the lipid-free body. These are illustrated in Fig. 2 which shows the weights of water and protein in the empty bodies of pigs over a range of weight from 2 to $90 \mathrm{~kg}$. The progressive increase in the protein:water ratio is particularly rapid during early growth. Superimposed on these more or less regular developmental changes are disturbances caused by environmental (especially nutritional) change, and in many pathological states. Table 1 shows the water and protein contents of the undernourished pigs described by Widdowson et al. (1960), compared with their age-matched or weight-matched controls.

Apart from changes in the proportions of water and protein other components of the lipid-free mass may vary; glycogen content, for example, though small, can vary widely as may the mineral composition of bone.

How well lipid-free body mass can be estimated from one of its components thus depends on the extent to which other factors affecting its composition may have varied. It seems to be a truism that when animals are subjected to environmental change the further from their normal circumstances they find themselves the more variable are their physiological responses likely to be. In a population of animals treated similarly except for differences in one factor, such as the protein content of the diet, it may be possible to predict their body composition much more accurately from one of its components, such as water or $\mathrm{K}$, than if a number of factors have varied simultaneously. In a homogeneous population it is possible to estimate body composition rather accurately from one simple variate.

In a homogeneous population it is even possible to rely on the constancy of energy utilization to estimate the amounts of lipid and lipid-free tissue. Kielanowski (1966) hypothesized that dietary energy is used almost entirely for only three purposes: maintenance, protein accretion and lipid deposition, each of which has a specific energy cost. Because the energy required to deposit $1 \mathrm{~kg}$ lipid is about six times that required to produce $1 \mathrm{~kg}$ of lipid-free tissue the rate of growth achieved with any given energy intake 


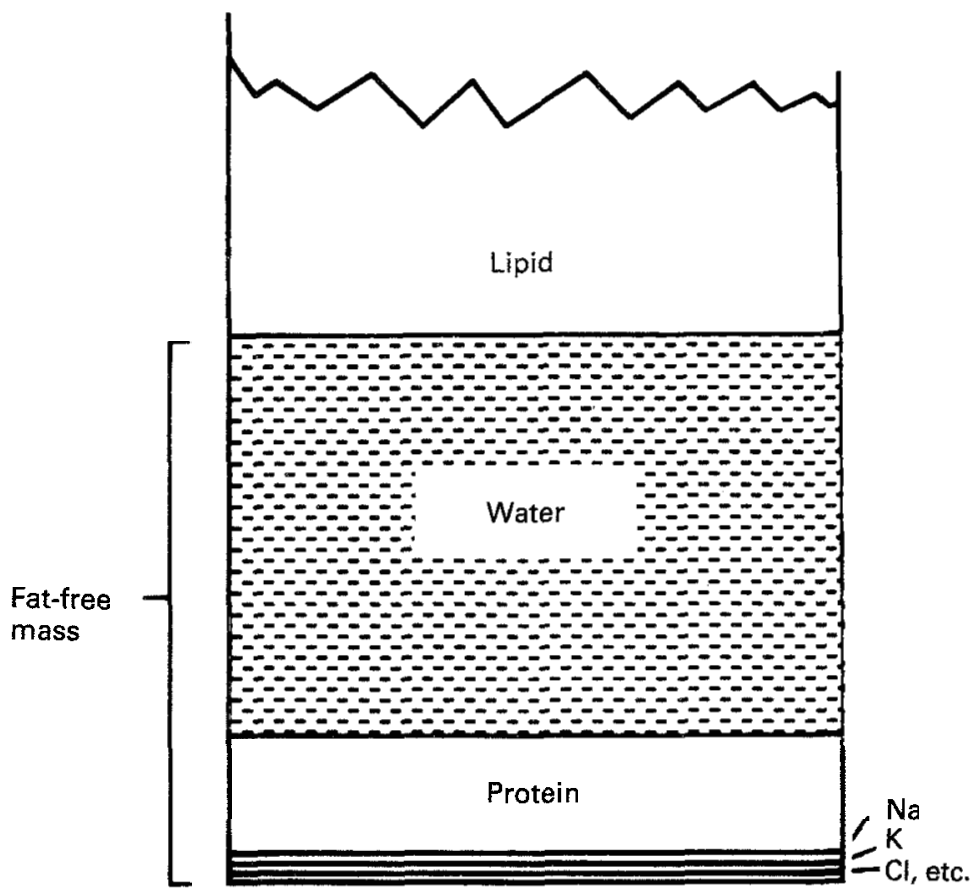

Fig. 1. Schematic description of the body as consisting of a fat-free mass of rather invariate composition with a variable superaddition of fat

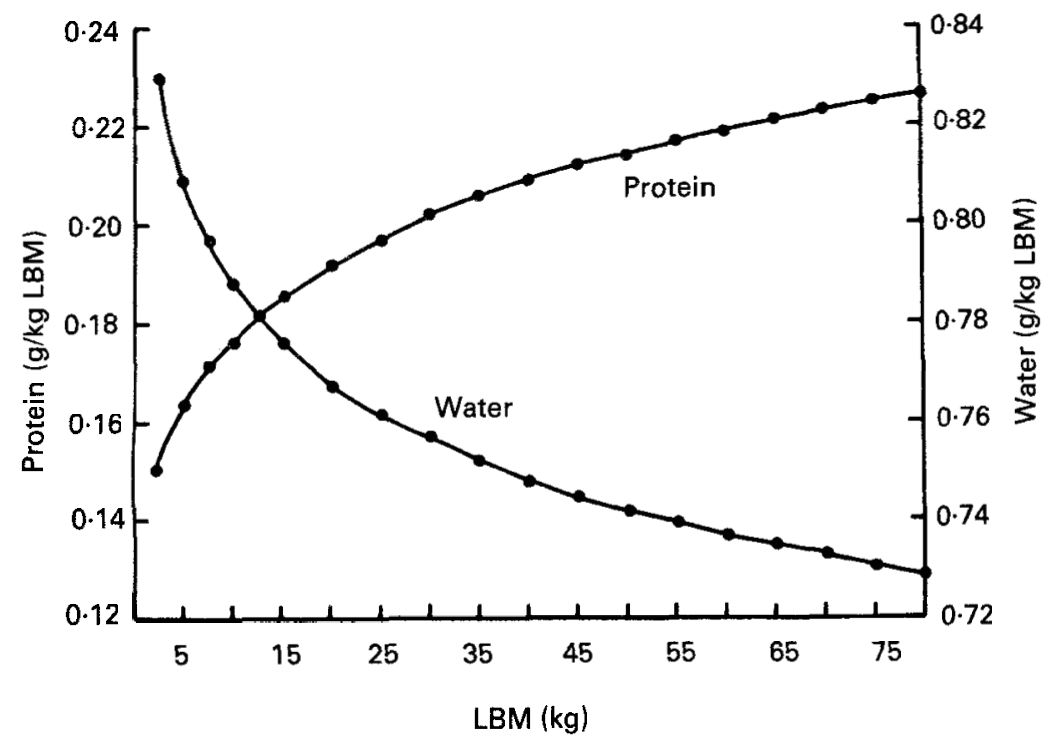

Fig. 2. Changes during growth in the protein and water contents of the lean body mass (LBM) of pigs (Kotarbinska, 1969). 
Table 1. The composition of skeletal muscle in normal and undernourished pigs

(Widdowson et al. 1960)

\begin{tabular}{|c|c|c|c|}
\hline & \multicolumn{2}{|c|}{ Controls } & \multirow[b]{2}{*}{ Undernourished } \\
\hline & Same age & Same weight & \\
\hline Water $(\mathrm{g} / \mathrm{kg})$ & 735 & 784 & 828 \\
\hline Vitrogen $(\mathrm{g} / \mathrm{kg})$ & $27 \cdot 8$ & $31 \cdot 1$ & 24.7 \\
\hline
\end{tabular}

is a function of the relative amounts of lipid-free mass and lipid gained. This concept has been used to estimate with remarkable accuracy the body composition of pigs under different nutritional regimens (Fowler. 1966; Houseman \& McDonald, 1973). This approach was used in a study with twenty-four pigs which had a mean body lipid content of $21 \mathrm{~kg}$ : body lipid was estimated with a residual standard deviation (RSD) of $0.95 \mathrm{~kg}$ (Houseman. 1972).

Where such constancy cannot be assumed, more direct methods of estimating lipid-free body mass are needed. The commonest have been those based on water or $\mathrm{K}$.

Water

A variety of substances equilibrate in body water and can be uscd as tracers. Most commonly employed are isotopes of hydrogen or oxygen, though tracers which equilibrate only in gastrointestinal water can additionally be valuable in distinguishing this compartment from the rest of the lipid-free body mass. Mainly because of exchange with labile atoms in other body constituents both $\mathrm{H}$ and $\mathrm{O}$ isotopes overestimate body water determined by dessication. $\mathrm{H}$ typically by $4 \%$. O by $1 \%$.

\section{$K$}

The only completely non-invasive method of estimating the body content of any element is by counting the emissions from the naturally occurring ${ }^{40} \mathrm{~K}$, with its relatively high natural specific activity. Low count rates and problems of counting geometry limit the precision of this method, especially with large animals and man (Kirton \& Pearson, 1963). These difficulties can be overcome by shielding to minimize background counts and by increasing the detector area:subject area ratio. With small animals like rats and mice close to 4- $\pi$ counting geometry can be achieved. but with man and large animals whole-body counters with adequate shiclding and multiple large detectors are required and such installations are necessarily expensive.

An alternative approach to estimating total body $\mathrm{K}$, by measuring the dilution of an administered dose of ${ }^{42} \mathrm{~K}$ (Pfau. 1966), allows the exchangeable body $\mathrm{K}$ to be estimated without specialized equipment, though necessarily exposing the subject to ionizing radiation. In two experiments with $90 \mathrm{~kg}$ pigs lipid-free body mass, with a mean value of approximately $60 \mathrm{~kg}$, was estimated with a RSD of $1.8 \mathrm{~kg}$ (Fuller et al. 1971) and $1.35 \mathrm{~kg}$ (Houseman. 1972). 


\section{Neutron-activation analysis (NAA)}

A more complete description of the lipid-free body mass can be obtained by simultaneous measurement of a number of its constituent elements. This can be achieved by NAA. Determining the body contents of a number of elements simultaneously allows greater accuracy and precision in the estimation of lipid-free body mass and of body lipid. The development of various systems of NAA has opened up the possibility of measuring non-destructively the body contents of nine or more elements, accounting for 0.99 of hody mass. Using a delayed activation system the whole-body $\mathrm{N}$ content of living rats has been estimated with a precision (coefficient of variation (cv) $0 .(015)$ better than that of Kjeldahl analysis of the carcasses (cv 0.028; Preston et al. 1984). With larger animals. the problems of non-uniform irradiation and counting geometry increase but with appropriate calibration good agreement has been demonstrated with human cadavers (Beddoe et al. 1986). Similar precision was achieved in $70 \mathrm{~kg}$ pigs. with standard deviations (\%) of $\mathrm{N} 3 \cdot 5, \mathrm{O} 4 \cdot 9$, sodium $2 \cdot 4$, phosphorus $2 \cdot 2$, chloride $2 \cdot 9$. calcium $2 \cdot 9$ (Preston et al. 1985).

\section{The estimation of lipid by difference}

According to the simple model described by Fig. 1 the weight of lipid can be estimated as the difference between the weight of the lipid-free body and total body-weight, but this approach requires some further clarification. Lipid is not the only variable superaddition to the lipid-free body mass proper. One source of error is the contents of the alimentary and urinary tracts. The model requires either that only the digesta-frec or empty body is considered or that the weight of the digesta is sufficiently small and its composition sufficiently close to that of the empty lipid-free body for this source of error to be negligible. With a carefully designed protocol at the time of measurement this error can be reduced but, especially with ruminant animals, the variation in the amount and composition of the digesta can still be a source of substantial error in the estimation of body lipid by difference. It is also clear that in this approach all errors in estimating total body-weight. lipid-free weight and digesta weight accrue to the estimate of body lipid. To avoid these errors means are needed to estimate body lipid directly.

\section{Direct estimation of body lipid}

Approaches to the direct estimation of body lipid include body density and lipid-soluble tracers. The measurement of body density by underwater weighing is perhaps the best of the methods developed until now for the routine assessment of the body composition of human subjects who can be asked to hold their breath. Residual lung volume is then determined by gas dilution. Nevertheless, this can be difficult for very young, elderly or sick subjects. With living animals the method requires a combination of weighing the incompletely immersed animal with gas dilution to determine the volume of the unimmersed parts. An alternative approach using whole-body plethysmography has been proposed (Blaxter, 1955; Sheng et al. 1987) but the technical requirements are extremely stringent and no viable apparatus for large animals has yet been built. Direct measurement of body lipid has been attempted by estimating the dilution of gases in body lipid. Gases for this purpose should have a high partition cocfficient between lipid and water: those found suitable include cyclopropane (Kumar, 1957) which has a 
partition coefficient of $52: 1$. Its great disadvantage is its long equilibration time, $1 \cdot 5-2 \mathrm{~h}$ in rats, but much longer in man (Kumar, 1957). The inert gas krypton has also been used, both in its stable form and as the isotope ${ }^{85} \mathrm{Kr}$ (Hytten, 1964; Hytten et al. 1966). With new developments in measurement techniques this approach would appear to be worth re-examining. Ettinger et al. (1984) proposed a method of quantifying or imaging (or both) body lipid using positron emission tomography (PET) after inhalation of halothane (2-bromo-2-chloro-1,1,1-trifluoroethane) labelled with ${ }^{18} \mathrm{~F}$.

\section{$N A A$ for direct estimation of body lipid and energy}

The total heat of combustion of body tissues can be accounted for virtually completely from their contents of protein, lipid and glycogen. The elemental composition of these is shown in Table 2 . These three components are clearly distinguished on the basis of their contents of $\mathrm{N}$ and $\mathrm{O}$; their carbon: $\mathrm{H}$ ratios are rather similar. For the determination of body lipid or body energy it would, therefore, be highly desirable to be able to estimate, in addition to $\mathrm{N}$ and $\mathrm{O}, \mathrm{C}$ or $\mathrm{H}$ or both. If based on $\mathrm{H}$ a separate estimate of body water would be needed to distinguish the $\mathrm{H}$ in water from that in the other constituents. Equally, with $\mathrm{C}$, a separate measurement of $\mathrm{Ca}$ is needed to allow the $\mathrm{C}$ in bone mineral to be estimated.

Total body energy retention can be estimated accurately from $\mathrm{C}$ and $\mathrm{N}$ balances (Blaxter \& Rook, 1954; Nehring et al. 1959; Blaxter, 1962), the major error being introduced by the fact that not only lipid but also glycogen contains no $\mathrm{N}$. In many circumstances the error introduced into estimates of the change in body energy by ignoring changes in glycogen content will be negligible.

It is possible to measure whole-body $\mathrm{C}$ by counting the $4.43 \mathrm{MeV}$ gamma rays from inelastic scattering of fast neutrons by C nuclei (Kehayias et al. 1987; Oxby et ai. 1987). The major source of potential error appears to be the large background count to be subtracted.

Simultaneous measurement of $\mathrm{C}, \mathrm{H}, \mathrm{N}$ and $\mathrm{O}$ made possible by NAA methods should allow the total energy reserves of the body to be estimated with unprecedented precision in vivo.

\section{METHODS OF ESTIMATING TISSUE AND ORGAN VOLUMES}

If the body is seen, not as a mixture of chemicals but as an assemblage of tissues and organs, entirely different methods of assessing body composition are required. Historically, various attempts have been made to assess the fatness of animals from external measurements such as the limb circumference:length ratio. More recently, the distribution of adipose tissue in obese subjects has been related to the waist:hip circumference ratio (Ashwell et al. 1985).

The development of imaging techniques based on ultrasound, X-ray computed tomography (X-ray CT) and nuclear magnetic resonance (NMR) have, in the last decade or so, provided new tools for studies of this aspect of body composition. Since methods based on ultrasound and X-ray CT were described in our previous review (Foster et al. 1988) they will not be considered in detail here. 
Table 2. The elemental composition of the major energy-yielding constituents of the body

\begin{tabular}{llcccc}
\hline & Carbon & Hydrogen & Oxygen & Nitrogen \\
\hline Triacylglyccrols & 700 & 108 & 102 & 0 \\
Protein & 531 & 63 & 222 & 165 \\
Glycogen & 448 & 62 & 490 & 0 \\
\hline
\end{tabular}

\section{Magnetic resonance imaging (MRI)}

MRI has been developed primarily for medical imaging with emphasis on the detection of abnormalities. The principles of MRI have been described by Foster \& Hutchison (1988). Briefly, certain nuclei (generally in MRI those of $\mathrm{H}$ ) possess spin and a magnetic moment. In a magnetic field the magnetic moment precesses about the applied field direction at a frequency proportional to the intensity of the magnetic field $(42.5 \mathrm{MHz}$ at 1 Tesla). By irradiating with electromagnetic energy at the resonant frequency, the precession angle can be increased. For example, a radiofrequency (RF) pulse of sufficient amplitude or duration will induce spin inversion (termed a $180^{\circ}$ pulse). The spins precess as a package and, hence, are able to induce a signal in a receiver coil. The initial magnitude of this signal is proportional to the spin (i.e. proton) density in the sample. The energy used to excite the spins (i.e. to widen the precession angle) is lost by the process of spin-lattice relaxation, often called $T_{1}$ relaxation. During $T_{1}$ relaxation the spins, after manipulation to bring them into the correct orientation, induce signals in the receiver coil, of different amplitude depending on the time interval between excitation and measurement. The envelope of the set of signals is, for a simple system, an exponential with a time constant quoted as $T_{1}$. The actual value of $T_{1}$ depends on the molecular environment of the spins. For example, in free water $T_{1}$ is long because the magnetic interactions between protons (which induce the relaxation process) are infrequent. If, however, the protons are in a motionally constrained environment, such as water associated with the hydration layer of a protein, the initiations and, hence, the relaxation process are much faster and $T_{1}$ is short. Because of the constraints of the MRI experiment only protons of mobile molecules can be observed; hence, the major sources of NMR signal are the $\mathrm{H}$ nuclei in water and in the $\mathrm{CH}_{2}$ groups of triacylglycerols. The concentration of protons in adipose tissue is high but they are more constrained than those in water. Both proton density and relaxation time can be used to aid tissue discrimination. In the spin-warp imaging technique (Edelstein et al. 1980) the image is produced from a set of field echoes which are signals formed by manipulation of magnetic field gradients after excitation with a $90^{\circ} \mathrm{RF}$ pulse. This produces what is termed the $S_{1}$ or proton density signal. If the $90^{\circ}$ RF pulse is preceded by spin inversion. an $S_{2}$ signal can be produced in a similar manner but which contains $T_{1}$ information in addition to proton density. An image produced from the $S_{2}$ signal alone is called an 'inversion recovery' image and said to be ' $T_{1}$-weighted'. From a combination of the $S_{1}$ and $S_{2}$ signals the $T_{1}$ value of each image pixel can be calculated to produce a $T_{1}$ map of the object slice. Under specific imaging conditions, for tissues with $T_{1}$ values less than $300 \mathrm{~ms}$, there is a large change in the $S_{2}$ signal with change in $T_{1}$, so that, using the $S_{2}$ signal, good contrast (over 6:1) between adipose tissue and the muscle is achieved (Foster et al. 1984). We have recently explored the possibility of increasing contrast further by combining the information contained in the $S_{1}$ and $S_{2}$ signals. Taking images 
Table 3. Tissue discrimination using combined nuclear magnetic resonance (NMR) information

(For each the value given is the percentage of pixels correctly identified as belonging to the tissue in which the NMR signal was generated (M. F. Fuller, C. A. Glasbey and P. A. Fowler, unpublished results))

\begin{tabular}{cccc}
\hline \hline One image & Two images & Three images \\
\hline $\mathrm{S}_{1} 54$ & $\mathrm{~S}_{1}+\mathrm{T}_{1} 83$ & $\mathrm{~S}_{1}, \mathrm{~S}_{2}+\mathrm{T}_{1}$ \\
$\mathrm{~S}_{2} 70$ & $\mathrm{~S}_{2}+\mathrm{T}_{1} 80$ & 83 \\
$\mathrm{~T}_{1} 73$ & $\mathrm{~S}_{1}+\mathrm{S}_{2} 84$ & \\
\hline
\end{tabular}

from human subjects, we analysed the relationships between $S_{1}, S_{2}$ and $T_{1}$ in a large number of pixels identified as representative of muscle, adipose tissue, heart, liver, gut and kidney. The tissue discrimination which can be achieved with each signal alone and with the calculated $T_{1}$ is shown in Table 3 . The discrimination which can be achieved by combining the $S_{1}$ and $S_{2}$ signals is much better than with either alone or with $T_{1}$ calculated from them (M. F. Fuller, C. A. Glasbey and P. A. Fowler, unpublished results).

There appears to be good correspondence in terms of cross-sectional adipose tissue areas between NMR images and the carcass (Fuller et al. 1985). However, a single NMR image visualizes only one slice (which may be transaxial, saggital or coronal) which describes only a small proportion of the total body volume (typically, a slice thickness of $16 \mathrm{~mm}$ ). To estimate the volume of a tissue or organ it is necessary to make a series of images. Estimates by MRI of the volumes of test objects agreed closely with directly determined volumes with an error of only 0.4 (SE 1.6)\%. Estimates by MRI of the volume of mammary parenchymal tissue in goats was significantly higher but highly correlated $(r \quad 0.88)$ with the weight of tissue determined post-mortem (Fowler et al. 1990). To assess total body composition it is necessary to use data from multiple sequential slices or to use prediction equations relating the whole to a part. We have recently (P. A. Fowler, M. F. Fuller, C. A. Glasbey, G. McNeill, G. G. Cameron and M. A. Foster, unpublished results) studied the distribution of adipose tissue in human subjects (Fig. 3). Images were made at up to twenty-eight transaxial planes on each subject and total body adipose tissue volumes were calculated using a truncated cone model (Kvist et al. 1986). Four of the images were taken at easily identified anatomical planes (Plate 1) and we also assessed the loss of precision incurred by using only these four images. The correlation of total fat estimated by MRI with the average of six methods used simultaneously (P. A. Fowler, M. F. Fuller, C. A. Glasbey, G. McNeill and M. A. Foster, unpublished results) was 0.99 ; reducing the number of images to the four corresponding to the anatomical markers reduced this correlation to 0.97 .

The non-invasive nature of NMR imaging makes it an attractive method for longitudinal studies, especially with human subjects. We used it to examine the changes in the amount and distribution of adipose tissue during a period of weight loss in subjects on low energy intakes (Fuller et al. 1987).

Although NMR imagers are expensive and are unlikely to be bought for body composition work alone, they are becoming increasingly widely available in hospitals and there are likely to be increasing opportunities for their use in nutritional studies. For such work high-field machines (1-2 Tesla) using superconducting magnets are not necessary; 

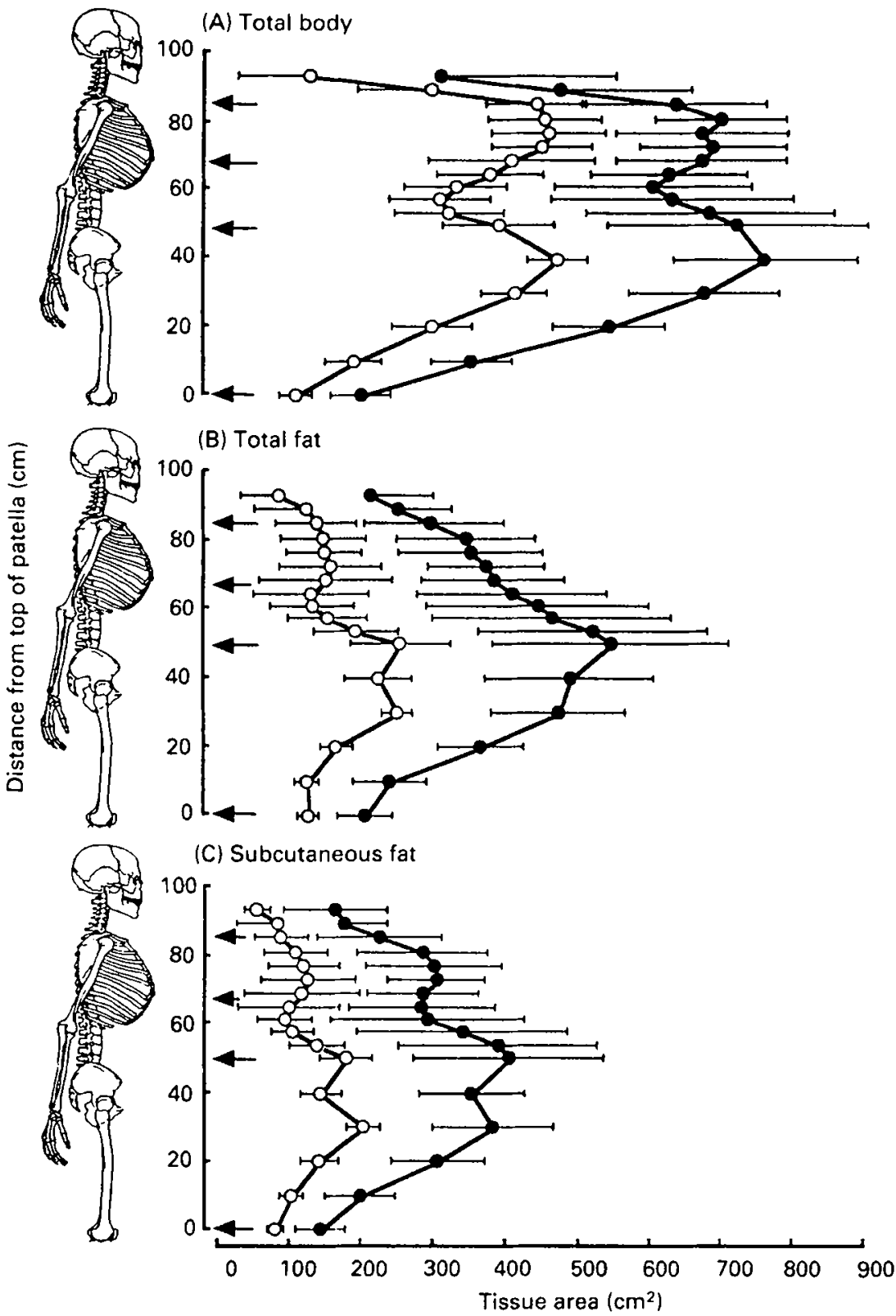

Fig. 3. The distribution between seventeen sites of (a) total body area, (b) total fat area, and (c) subcutaneous fat area in $(\bullet)$ lean and $(\bullet)$ obese women. $\leftarrow$, Location of the four anatomically determined planes (Fowler et al. 1990). Points are means with their standard errors represented by horizontal hars. 


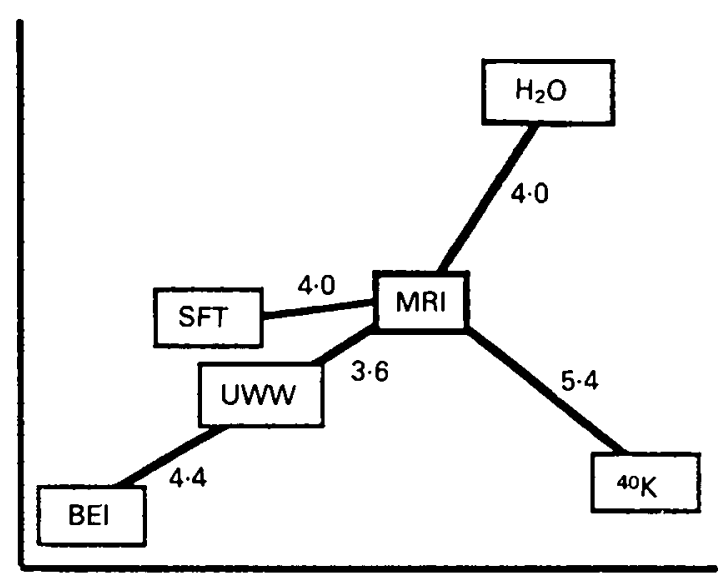

Fig. 4. Comparison of magnetic resonance imaging (MRI), skinfold thickness (SFT). underwater weighing (UWW). body electrical impedance (BEI). whole-body counting ( ${ }^{4} \mathrm{~K}$ ) and body water from ${ }^{2} \mathrm{H}$ and ${ }^{18} \mathrm{O}$ dilution $\left(\mathrm{H}_{2} \mathrm{O}\right)$ : a two-dimensional projection of fourtecn dimensional points of predicted percentage fat in lean and obese women, with minimum spanning tree and Euclidean distances superimposed (Fowler et al. 1990).

although higher fields facilitate other applications such as spectroscopy and chemical shift imaging they have little advantage for the present purposes over machines with fields of less than $0 \cdot 1$ Tesla.

\section{EVALUATION OF METHODS \\ Calibration and validation}

Any new technique must be calibrated (if a calibration cannot be derived from known physical or chemical variables) and validated. It is important, unless the range of size, weight, age etc. in the group of subjects used for these purposes is similar to that of the future experimental subjects on whom the technique is to be applied, that the contributions of variables such as size, weight and age are considered. In this regard, since correlations depend on the range of the data, the RSD is generally a more useful measure of the precision of the technique. It is frequently the case that high correlations are reported between estimates of, say, body fat made by a new method and body fat directly determined with subjects covering such a range of body-weight that this factor alone would be expected to account for much of the variation in fatness. What one needs to know is not the predictive power of the new measure on its own but how much it improves on estimates made from simple variables such as size, weight and age. It can be chastening to discover how little the RSD is reduced by the addition of a rather sophisticated measure of fatness! The cost of a small increase in precision can be rather high.

\section{Comparison of methods}

Faced with an array of techniques, new and old, the choice of a method is not easy. though considerations of access and cost are often paramount these days. We have recently made a comparison, in lean and obese women, of six methods: skinfold thickness, underwater weighing, whole-body ${ }^{+1} \mathrm{~K}$ counting, total body water, tetrapolar 

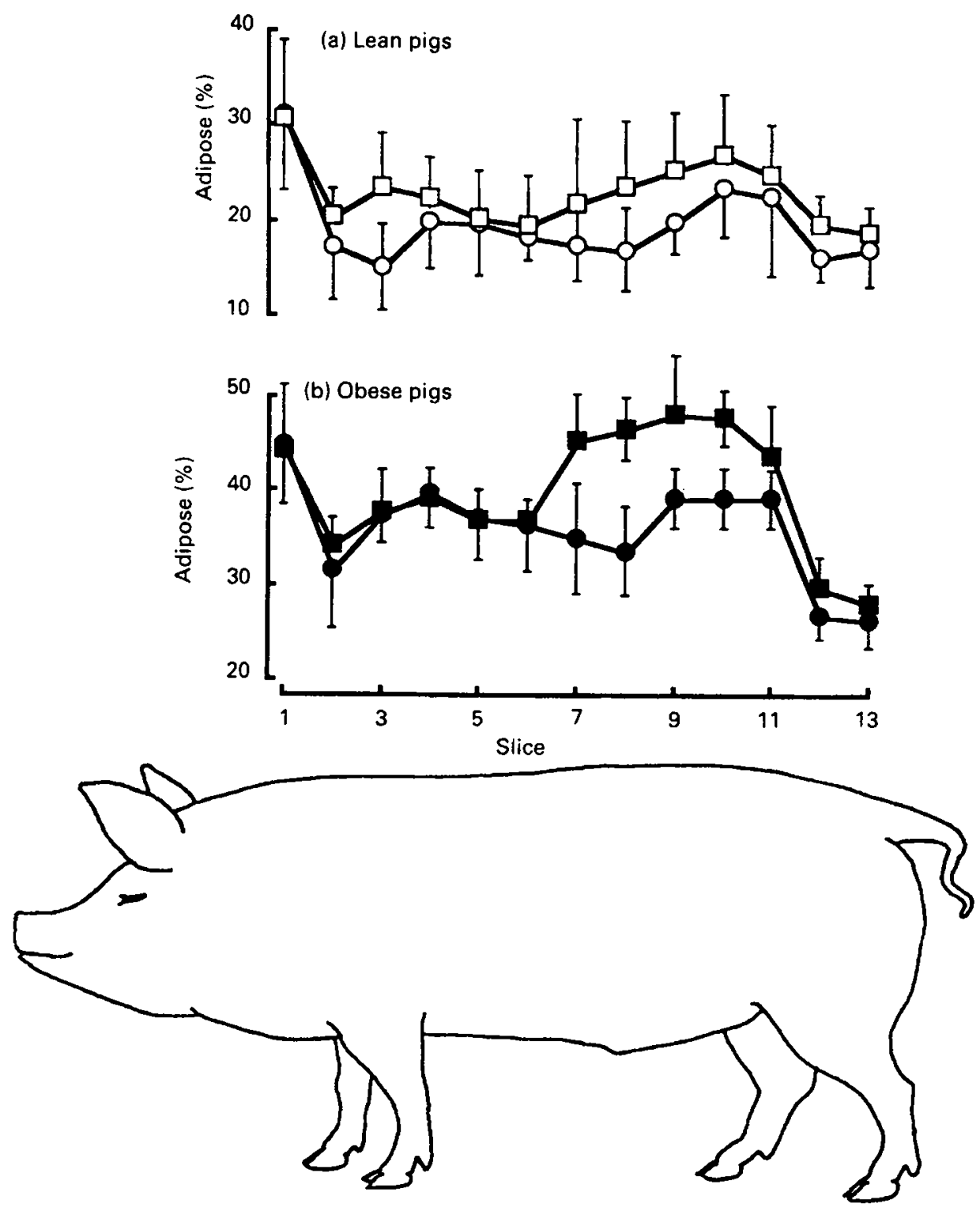

Fig. 5. The percentage of adipose tissuc in (a) lean and (b) obese pigs: a comparison of distribution determined by magnetic resonance imaging $(\square, 0)$ and by carcass dissection $(0, \bullet)(P$. A. Fowler, M. F. Fuller, C. A. Glasbey, G. McNeill, G. G. Cameron and M. A. Foster, unpublished results). Points are means with their standard errors represented by vertical bars. 

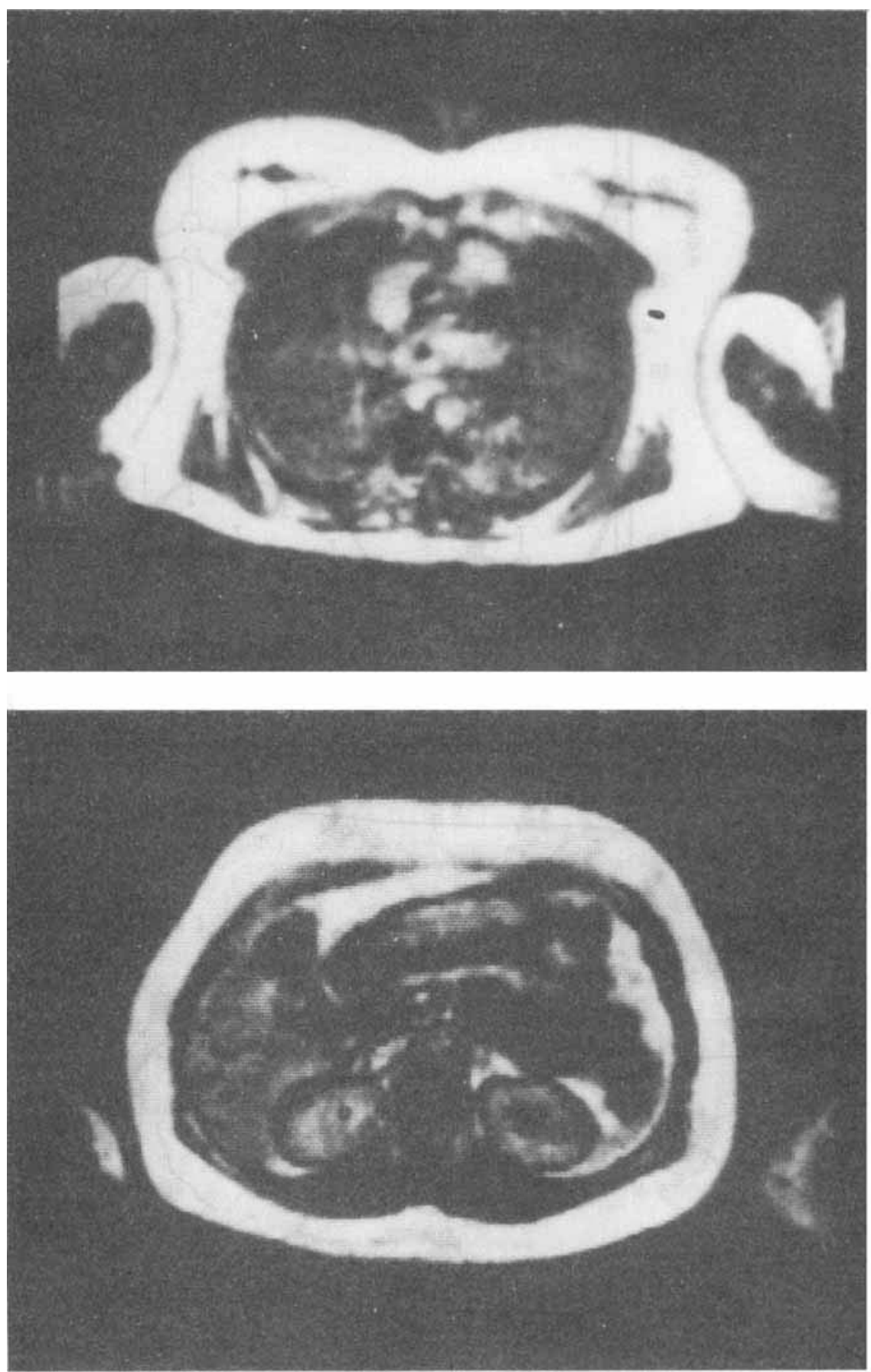

(b)

M. F. FULLER AND OTHERS 

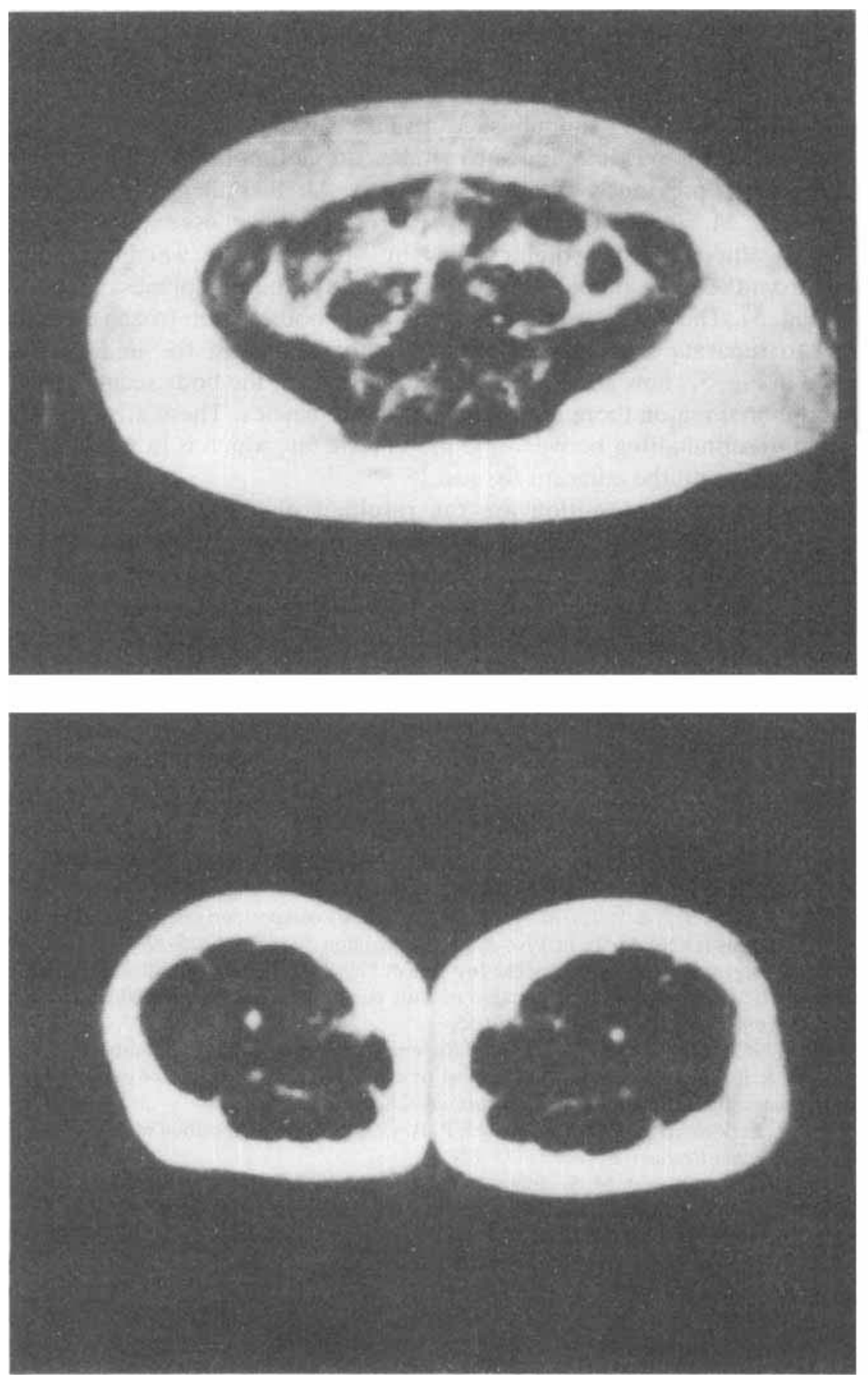

M. F. FULLER AND OTHERS 
bioelectrical impedance and NMR (McNeill et al. 1989). Although there is no 'absolute in vivo measure of body composition against which the estimates may be compared principal component analysis showed that the estimatc by MRI was much the closest (Fig. 4) to the mean of all six methods (P. A. Fowler, M. F. Fuller, C. A. Glasbey, G. McNeill and M. A. Foster, unpublished results). In animals, on the other hand, direct validation of MRI is possible and such studies are an important adjunct to the human studies described previously. We (P. A. Fowler, M. F. Fuller, C. B. Glasbey, G. G. Cameron and M. A. Foster, unpublished results) have used pigs to compare the estimates of adipose tissue volume made by MRI with the weight of adipose tissuc dissected from the same animal. Images were made at thirteen planes along the length of the pig (Fig. 5). The pigs were then killed and the bodies were frozen and sliced with a bandsaw to separate slices corresponding to the planes of the images. The results, illustrated in Fig, 5, show good concordance for most of the body sections, but for those in the abdominal region there are significant discrepancies. These arise largely from the difficulty in discriminating between the mesenteric fat, which is in small and complexly shaped deposits, and the adjacent tissues.

Changes in body composition are the resultant of changes in the metabolism of nutrients, principally in the rates of synthesis and oxidation of protein and the storage and mobilization of triacylglycerols. To understand how body composition is controlled we need to understand how each of those underlying processes is individually controlled and how those controls are coordinated to meet functional needs. That is a challenge that will require the collaborative efforts of scientists in a number of different disciplines. Improved methods of monitoring changes in body composition will be an important part of that effort.

\section{REFERENCES}

Ashwell, M. Cole, T. J. \& Dixon, A. K. (1985). Obesity: new insight into the anthropometric classification of fat distribution shown by computed tomography. British Medical Journal 290, 1692-1694.

Beddoe, A. H., Streat, S. J. \& Hill, G. L. (1986). Clinical body composition assessment using in vivo neutron activation analysis (IVNAA). In In Vivo Body Composition Studies, pp. 25-32 [K. J. Ellis, S. Yasumura and W. D. Morgan, editors]. London: The Institute of Physical Sciences in Medicine.

Blaxter, K. L. (1955). A note on the estimation of body composition in pigs. Agriculture and Food Research Council Subcommittee on Pig Nutrition, 491/55.

Blaxter, K. L. (1962). The Energy Metabolism of Ruminants, p. 51. London: I Iutchinson.

Blaxter, K. L. \& Rook, J. A. F. (1954). The heat of combustion of the tissues of cattle in relation to their chemical composition. British Journal of Nutrition 7, 83-91.

Coward, W. A., Parkinson, S. A. \& Murgatroyd, P. R. (1988). Body composition measurements for nutrition research. Nutrition Research Review 1, 115-124.

Edelstein, W. A., Hutchison, J. M. S., Johnson, G. \& Redpath, T. W. (1980). Spin-warp NMR imaging and applications to human whole-body imaging. Physics in Medicine and Biology 25, 751-756.

Ettinger, K. V., Foster, M. A. \& Miola, U. J. (1984). Future developments in the in vivo measurement of body composition in pigs. In In Vivo Measurement of Body Composition in Meat Animals, pp. 207-233 [D. Lister, editor]. London: Elsevier.

Foster, M. A., Fowler, P. A., Fuller, M. F. \& Knight, C. H. (1988). Non-invasive methods for assessment of body composition. Proceedings of the Nutrition Society 47, 375-385.

Foster, M. A. \& Hutchison, J. M. S. (1988). Practical NMR Imaging. Oxford: IRL Press Ltd.

Foster, M. A., Hutchison, J. M. S., Mallard, J. R. \& Fuller. M. F. (1984). Nuclear Magnetic Resonance pulse sequence and discrimination of high- and low-fat tissues. Magnetic Resonance Imaging 2, 187-192.

Fowler, P. A., Knight. C. H., Cameron, G. G. \& Foster, M. A. (1990). Use of magnetic resonance imaging in the study of goat mammary glands in vivo. Journal of Reproduction and Fertility (In the Press). 
Fowler, V. R. (1966). Prediction of carcase composition of pigs from efficiency of feed utilisation with correction for maintenance requirement. Proceedings 9th International Congress of Animal Production, $\mathrm{p}$. 79. Edinburgh: Oliver and Boyd.

Fuller, M. F., Foster, M. A. \& Hutchison, J. M. S. (1985). Estimation of body fat by nuclear magnetic resonance imaging. Proceedings of the Nutrition Society 44, $108 \mathrm{~A}$.

Fuller, M. F., Houseman, R. A. \& Cadenhead, A. (1971). The measurement of exchangeable potassium in living pigs and its relation to body composition. British Journal of Nutrition 26, 203-214.

Fuller, M. F., Stratton, S. M., Geddes, D., Fowler, P. A. \& Foster, M. A. (1987). A study of the sites of adipose tissue loss by NMR imaging. In In Vivo Body Composition Studies, pp. 55-59 [K. J. Ellis, S. Yasumura and W. D. Morgan, editors]. London: Institute of Physical Sciences in Medicine.

Houseman, R. A. (1972). Studies of methods of estimating body composition in the pig. PhD Thesis, University of Aberdeen.

Houseman, R. A. \& McDonald, I. (1973). The prediction of body composition in bacon pigs from measurements of feed intake and live-weight gain. Animal Production 17, 295-304.

Hytten, F. (1964). Measurement of total body fat in man with ${ }^{85}$ krypton. Proceedings of the Nutrition Society 23, xxi.

Hytten, F., Taylor, K. \& Taggart, N. (1966). Measurement of total body fat in man by absorption of ${ }^{85} \mathrm{krypton}$. Clinical Science 31, 111-119.

Kehayias, J. J., Ellis, K. J., Cohn, S. H., Yasumura, S. \& Weinlein, J. H. (1987). Use of a pulsed neutron generator for in vivo measurement of body carbon. In In Vivo Body Composition Studies, pp. 427-435 [K. J. Ellis, S. Yasumura and W. D. Morgan, editors]. London: Institute of Physical Sciences in Medicine.

Kempster, A. J. (1984). Cost-benefit analyses of in vivo estimates of body composition in meat animals. In In Vivo Measurement of Body Composition in Meat Animals, pp. 191-204 [D. Lister, editor]. London: Elsevier.

Kielanowski, J. (1966). Conversion of energy and the chemical composition of gain in bacon pigs. Animal Production 8, 121-128.

Kirton, A. H. \& Pearson, A. M. (1963). Relation between K content and body composition. Annals of the New York Academy of Sciences 110, 221-228.

Kissebah, A. H., Vydelingum, N., Murray, R., Evans, D. J., Hartz, A. J., Kalkhoff, R. K. \& Adams, P. W. (1982). Relation of body fat distribution to metabolic complications of obesity. Journal of Clinical Endocrinology and Metabolism 54, 254-260.

Kotarbinska, M. (1969). Badania nad przemiana energii u rosnacych swin. Wlasne Instytut Zootechniki, Wroclaw no. 238.

Krotkiewski, M., Bjorntorp, P., Sjostrom, L. \& Smith, U. (1983). Impact of obesity on metabolism in men and women - importance of regional adipose tissue distribution. Journal of Clinical Investigation 72, 1150-1162.

Kumar, I. (1957). A comparison of direct and indirect methods of determining body composition. PhD Thesis, University of Aberdeen.

Kvist, H., Sjostrom, L. \& Tylen, U. (1986). Adipose tissue volume determinations in women by computed tomography: technical considerations. International Journal of Obesity 10, 53-67.

McNeill G., Fowler, P. A., Maughan, R. J., McGaw, B. A., Gvozdanovic, S., Gvozdanovic, D. \& Fuller, M. F. (1989). Body fat in lean and obese women by six methods. Proceedings of the Nutrition Society 48, $23 \mathrm{~A}$.

Nehring, K., Hoffmann, L. \& Schiemann, R. (1959). Die Verwertung der Futterenergie in Abhangigkeit vom Ernahrungsniveau. Archiv für Tierernahrung 9, 85-139.

Oxby, C. B., Oldroyd, B., Krupowicz, D. W., Moore, S. C., Brooks, K., Yankuba, S., Forster, S. \& Burkinshaw, L. (1987). A clinical facility for the measurement of total body carbon. In In Vivo Body Composition Studies, pp. 421-426 [K. J. Ellis, S. Yasumura and W. D. Morgan, editors]. London: Institute of Physical Sciences in Medicine.

Pfau, A. (1966). Estimation of weight of body parts by ${ }^{42} \mathrm{~K}$ dilution method (pig). Landwirtschaftliche Forschung Sonderheft 20, 139-142.

Preston, T. R., Fuller, M. F., East, B. W. \& Bruce, I. (1985). Preliminary experiments to assess the suitability of whole-body neutron activation for body composition analysis in $70 \mathrm{~kg}$ pigs. Proceedings of the Nutrition Society 44, 109A.

Preston, T. R., Reeds, P. J., East, B. W. \& Holmes, P. H. (1984). A comparison of body protein determination in rats by in vivo neutron activation and carcass analysis. Clinical Science 68, 349-355.

Rebuffe-Scrive, M., Enk, L., Crona, N., Lonroth, P., Abrahamsson, L., Smith, U. \& Bjorntorp, P. (1985). Fat cell metabolism in different regions in women: effect of menstrual cycle, pregnancy and lactation. Journal of Clinical Investigation 75, 1973-1976. 
Sheng, H.-P., Dang, T., Adolph, A. L., Schanler, R. J. \& Garza, C. (1987). Infant body volume measurement by acoustic plethysmography. In In Vivo Body Composition Studies, pp. 415-420 [K. J. Ellis, S. Yasumura and W. D. Morgan, editors]. London: Institute of Physical Sciences in Medicine.

Widdowson, E. M., Dickerson, J. W. T. \& McCance, R. A. (1960). Severe undernutrition in growing and adult animals. 4. The impact of severe undernutrition on the chemical composition of the soft tissues of the pig. British Journal of Nutrition 14, 457-471.

\section{EXPLANATION OF PLATE}

Plate 1. Cross-section of inversion recovery magnetic resonance images at the four (a-d) anatomically determined planes described in Fig. 3. 